\title{
Improving Health Care Efficiency with Lower Cost Services
}

\author{
Ronald Lagoe*, Emmi Lagoe \\ Hospital Executive Council, Syracuse, NY, USA \\ Email: *Hospexcl@cnymail.com
}

How to cite this paper: Lagoe, R. and Lagoe, E. (2019) Improving Health Care Efficiency with Lower Cost Services. Case Reports in Clinical Medicine, 8, 231-238. https://doi.org/10.4236/crcm.2019.88028

Received: July 26, 2019

Accepted: August 25, 2019

Published: August 28, 2019

Copyright (C 2019 by author(s) and Scientific Research Publishing Inc. This work is licensed under the Creative Commons Attribution International License (CC BY 4.0).

http://creativecommons.org/licenses/by/4.0/

\begin{abstract}
This study described Subacute and Complex Care Programs developed by the Syracuse hospitals to reduce the expenses of extended hospital stays. They focused on the movement of patients for services such as dialysis and complex care. These programs involved costs of approximately $\$ 7100$ to $\$ 10,600$ per patient compared with $\$ 12,600$ to $\$ 25,000$ per patient for extended stays in hospitals. The study also suggested that substantial savings were generated in the service area of the Syracuse hospitals by reducing inpatient adult medicine and adult surgery hospital rates. The annual savings for these services were substantial, \$4,600,000 for 2017 when compared with 2011.
\end{abstract}

\section{Keywords}

Hospitals, Nursing Homes, Health Care Expenses

\section{Introduction}

Historically, health care expenses have been a major concern for governments, businesses, and individuals in the United States and elsewhere. These expenses have consumed an increasing proportion of national income. Addressing these expenses has been a challenge for the public and private sectors of the economy [1].

Recently, attention concerning health care expenses has begun to focus on the price of care. It has been demonstrated that prices and expenses for health care in the United States are substantially higher than in other developed nations [2] [3] [4].

This discussion concerning health care costs has included a recognition that these expenses will be difficult to reduce. Because health care is a labor-intensive process, it would include reducing large numbers of staff from provider and payer organizations [5]. 
During the past several decades, numerous efforts to reduce health care costs by shifting expenses among providers have been evaluated. It has been suggested that these initiatives have potential for limiting the actual costs of care [6] [7].

Many efforts to address health care expenses have involved shifting utilization from high-cost providers such as hospitals. It has been suggested that this approach could limit the use of high-cost services and reduce expenses by moving some services to less costly settings such as long term care and ambulatory care [8] [9].

Shifting health care expenses from hospitals to nursing homes has been useful because it includes the opportunity to address patients who require high-cost inpatient care. They include medicine patients who require extended hospitalization for medications and surgical patients who need wound care. They could also include patients with low severity of illness who have been admitted for inpatient care.

In the United States, programs that involve shifting health care expenses to less costly providers have been developed within communities. Because health care is delivered at this level, it offers opportunities for reducing expenses and improving outcomes of care.

\section{Population}

This study identified examples of approaches to shifting health care from hospital inpatient to other settings of care in the metropolitan area of Syracuse, New York. This area includes three large acute care hospitals, Crouse Hospital (19,611 inpatient discharges excluding well newborns, 2018), St. Joseph's Hospital Health Center (25,394 inpatient discharges, 2018), and Upstate University Hospital 32,877 inpatient discharges, 2018).

The Syracuse hospitals provide primary and secondary acute care to an immediate service area of approximately 600,000. They also provide tertiary services to the eleven county Central New York Health Service Area with a population of 1,400,000. The largest population within this area, 365,763, includes Onondaga County and the City of Syracuse. Counties adjacent to Onondaga include an additional population of 248,508. Counties in the rest of the Central New York Region include a population of 510,310.

Historically, the Syracuse hospitals have worked to improve the efficiency and outcomes of care through a number of approaches. These have included efforts to reduce inpatient lengths of stay and admissions through cooperation with local long term care providers. They have also included support for ambulatory care services through medical observation, ambulatory surgery, and other forms of outpatient care. A number of these efforts have been developed through the Hospital Executive Council, a joint planning organization of the hospitals [10].

\section{Method}

This study reviewed examples of efforts to improve the efficiency of inpatient 
care through substitution of services in the metropolitan area of the Syracuse hospitals. These examples addressed inpatient lengths of stay and admissions/discharges.

During the past several decades, the reduction of inpatient lengths of stay has been a priority of the hospitals because of their impact on organizational expenses. Extended inpatient stays have contributed to health costs through expenses for labor, pharmaceuticals, and tests. Limiting stays have included reduction of these important costs.

Efforts to reduce inpatient stays in the Syracuse hospitals have included shifting portions of inpatient stays to nursing homes and other long term care providers. Nursing homes have offered an opportunity for this process because they provide 24-hour, seven-day care. As a result, they can support extended care for patients who cannot be discharged home.

To address this need, the Syracuse hospitals developed the Subacute and Complex Care Programs through cooperation with area long term care providers. Each of these programs involved shifting some portion of extended inpatient care from hospital to long term care settings.

The Subacute Patient Transportation Program involved movement of patients requiring offsite dialysis from hospital inpatient to nursing home settings. Because existing health care payers did not support the costs of this transportation, most of it was provided by the hospitals.

The Complex Care Programs involved movement of portions of extended inpatient therapies from hospital to nursing home settings. These therapies included intravenous antibiotic care for infections and other conditions. They also addressed extended wound care. The costs of some of these services, including medications, wound care, and other therapies, were provided by the hospitals to the nursing homes through the Hospital Executive Council.

This study identified the impact of these services on inpatient lengths of stay in the Syracuse hospitals during a fourteen-year period. It identified changes in stays and the estimated inpatient expenses saved through this process. Data for this analysis were generated by the Hospital Executive Council.

The Syracuse hospitals have also improved the efficiency of care through limitation and reduction of inpatient admissions. This process has involved the major inpatient services, adult medicine and adult surgery.

Limitation of admissions for adult medicine, the largest inpatient service, has included the use of medical observation to shift short-stay inpatients to outpatient care. It has also included efforts to support additional ambulatory care services. These efforts have resulted in a reduction in the rate of increase of adult medicine admissions/discharges in the hospitals.

For adult surgery, this activity has included the continued development of ambulatory surgery services by hospitals and other providers. This activity has also included shifting some inpatient procedures for relatively healthy patients to ambulatory settings. The programs have resulted in a reduction in inpatient surgery discharges in hospitals. 
This study identified the impact of limitation and reduction of inpatient adult medicine and adult surgery admissions in the service area of the Syracuse hospitals between 2011 and 2017. Data for this component of the study were obtained from the New York State Planning and Research Cooperative System (SPARCS). This impact was identified through numbers of inpatient admissions/discharges and through discharges per 1000 resident population.

\section{Results}

The initial component of the study focused on programs that improved the efficiency of health care by shifting services from inpatient hospitals to nursing homes in the service area of the Syracuse hospitals. Relevant data are summarized in Table 1.

This information includes the utilization of services that were moved from the end of acute care stays to long term care facilities. This process was supported by Program Development Funds provided by the Syracuse hospitals through the Hospital Executive Council. For each service, the expenses of care in the nursing homes combined with the Program Development Funds were considerably lower than the expenses of maintaining these patients in acute hospitals.

Patients for the Subacute and Complex Care Programs were selected by hospital case management staff in cooperation with nursing home admission staff. This process included evaluation of patient needs, Subacute and Complex Care Program resources, and nursing home capabilities.

The most basic of these services was the Subacute Offsite Services Program. This effort focused on patients who remained in hospitals for extended periods because of the need for dialysis and other acute care services. These patients were not candidates for discharge home. Through the program, the Syracuse hospitals provided funds for transportation to dialysis and other services so that these patients could be discharged to long term care facilities, rather than remaining in hospitals. The expenses of this program, approximately $\$ 1800$ plus

Table 1. Long Term Care Subacute \& Complex Care Programs, Syracuse Hospitals, 2004-2018.

\begin{tabular}{lccccccccc}
\hline & \multicolumn{4}{c}{ Number of Patients } & \multicolumn{2}{c}{$\begin{array}{c}\text { Total Program } \\
\text { Development }\end{array}$} \\
\cline { 2 - 8 } & 2004 & 2006 & 2008 & 2010 & 2012 & 2014 & 2016 & 2018 & Funds \\
\hline Offsite Services & - & - & 15 & 27 & 13 & 24 & 41 & 66 & $\$ 319,650$ \\
IV Medications & 72 & 60 & 54 & 40 & 39 & 40 & - & - & $\$ 228,750$ \\
Enhanced Medications & - & - & 22 & 14 & 9 & 34 & 11 & - & $\$ 113,050$ \\
Extended Wound Care & - & 18 & 9 & 7 & 7 & 19 & 2 & - & $\$ 124,000$ \\
Complex Care Programs & - & - & - & - & - & 7 & 23 & 45 & $\$ 324,600$ \\
Total & 72 & 78 & 100 & 88 & 68 & 124 & 77 & 111 & $\$ 1,110,050$ \\
\hline
\end{tabular}

Source: Hospital Executive Council. 
$\$ 5300$ for nursing home reimbursement per patient, were much less than those of several weeks of additional acute care. The Program is still in operation.

Additional Subacute Programs developed in Syracuse focused on Program Development Funds to reduce hospital stays by moving services from the end of stays in acute hospitals to stays in nursing homes. These programs included funds for intravenous medications, other medications, and extended wound care. The Program Development Funds enabled the hospitals to discharge these patients sooner and the nursing homes to support what would have been the last weeks of their acute care stays.

The additional Subacute Programs included support from the Syracuse hospitals for Intravenous Therapy, \$750 per patient, Enhanced Medications, \$1256 per patient, and Extended Wound Care, \$2385 per patient. For each patient, an additional $\$ 3200$ would be required for nursing home reimbursement. These expenses were considerably lower than those of maintaining these patients in acute hospitals for several weeks, approximately $\$ 12,000$ per patient. Eventually, these services were supported completely by the nursing homes and the Subacute Programs were phased out.

The services moved from acute care in the Syracuse hospitals to nursing homes in the community also included Complex Care. Most of these services involved extended care for high-cost medications such as meripenum and daptomycin. The high costs of these medications made it necessary for nursing homes to obtain additional support in order to provide them. The hospitals generated this support through Program Development Funds.

Since implementation in 2014, the Complex Care Programs have cost \$4328 in Program Development Funds plus an additional \$6300 in nursing home reimbursement cost per patient. These expenses were considerably lower than those of extended stays in acute hospitals would have been, approximately $\$ 12,600$ $\$ 25,000$ per patient. The Complex Care Programs are still in operation.

The increase in efficiency supported by the Subacute and Complex Care Programs was associated with a reduction in adult medical/surgical stays in the Syracuse hospitals from 5.43 to 5.04 days between 2004 and 2018. This reduction in stays resulted in the elimination of 23,000 patient days or an average daily census of 63 .

The second component of the study focused on limitation of hospital inpatient adult medicine and adult surgery admissions/discharges per population. Relevant data are identified in Table 2.

This information demonstrated that, between 2011 and 2017, resident inpatient adult medicine and discharges declined in the immediate service area of the Syracuse hospitals, Onondaga County. This reduction amounted to 920 discharges or 3.9 per 1000 resident population. This reduction saved approximately $\$ 4,600,000$ in health care expenses related to these admissions and discharges between 2011 and 2017.

The data also indicated that, by 2017, adult medicine and adult surgery discharges for Onondaga County were 3.4 per 1000 population lower than in the 
Table 2. Resident inpatient hospitalization per 1000 population, medical/surgical discharges, New York state metropolitan areas, 2011-2017.

\begin{tabular}{|c|c|c|c|c|c|c|c|c|}
\hline & \multicolumn{2}{|c|}{2011} & \multicolumn{2}{|c|}{2013} & \multicolumn{2}{|c|}{2015} & \multicolumn{2}{|c|}{2017} \\
\hline & $\begin{array}{l}\text { Number of } \\
\text { Discharges }\end{array}$ & $\begin{array}{c}\text { Discharge } \\
\text { Rate per } \\
1000 \\
\text { Population }\end{array}$ & $\begin{array}{l}\text { Number of } \\
\text { Discharges }\end{array}$ & $\begin{array}{c}\text { Discharge } \\
\text { Rate per } 1000 \\
\text { Population }\end{array}$ & $\begin{array}{l}\text { Number of } \\
\text { Discharges }\end{array}$ & $\begin{array}{c}\text { Discharge } \\
\text { Rate per } 1000 \\
\text { Population }\end{array}$ & $\begin{array}{l}\text { Number of } \\
\text { Discharges }\end{array}$ & $\begin{array}{c}\text { Discharge } \\
\text { Rate per } 1000 \\
\text { Population }\end{array}$ \\
\hline \multicolumn{9}{|l|}{ Resident County } \\
\hline Capital District & 40,683 & 83.6 & 35,397 & 72.2 & 43,780 & 88.4 & 48,994 & 98.5 \\
\hline \multicolumn{9}{|c|}{ (Albany, Schenectady, Rensselaer) } \\
\hline Erie County & 67,269 & 93.9 & 70,233 & 98.6 & 66,614 & 90.9 & 71,707 & 97.6 \\
\hline \multicolumn{9}{|l|}{ (Buffalo) } \\
\hline Monroe County & 58,315 & 101.5 & 53,761 & 93.2 & 53,283 & 90.9 & 57,933 & 98.6 \\
\hline \multicolumn{9}{|l|}{ (Rochester) } \\
\hline New York City & 672,497 & 104.9 & 628,873 & 97.5 & 610,212 & 90.0 & 608,803 & 88.9 \\
\hline \multicolumn{9}{|l|}{ (5 Burroughs) } \\
\hline Oneida County & 23,142 & 126.4 & 20,899 & 113.9 & 20,910 & 114.9 & 21,455 & 118.0 \\
\hline \multicolumn{9}{|l|}{ (Utica) } \\
\hline Onondaga County & 35,555 & 99.0 & 34,536 & 95.7 & 35,058 & 96.2 & 34,635 & 95.1 \\
\hline (Syracuse) & & & & & & & & \\
\hline
\end{tabular}

Data exclude obstetrics (APR DRGs 540-566), neonates (APR DRGs 580-640), mental health/substance abuse treatment (APR DRGs 740-776), rehabilitation (APR DRG 860), and all patients aged 0 - 17 years. Sources: New York Statewide Planning and Research Cooperative System (SPARCS) (resident discharges); Cornell Population Projections (May 2019) (population).

Capital District, 2.5 per 1000 population lower than in Erie County, 3.5 per 1000 population lower than in Monroe County, and 22.9 per 1000 population lower than in Oneida County. This information indicated that the lower admission/discharges rates in the Syracuse area were responsible for a savings of $\$ 833,000$ - $\$ 2,457,000$ compared with the other areas.

The data also indicated that the 2017 rates in Syracuse were 6.2 per 1000 population higher than those in New York City. Discharge rates per 1000 population in New York City also declined between 2011 and 2017.

Data collected by the Hospital Executive Council indicated that adult medicine discharges per population in the Syracuse area declined because of the impact of medical observation programs and use of ambulatory care services. For the combined hospitals, medical observation programs accounted for $24-26$ percent of observation and adult medicine inpatients combined. The use of ambulatory care and primary care services has increased in recent years as a result of competition among the hospitals.

The Syracuse hospitals have used ambulatory surgery programs to limit adult surgery discharges for more than forty years. The ambulatory surgery program at Crouse Hospital was one of the first in the nation. Utilization of these programs continues to increase. 


\section{Discussion}

Health care expenses continue to challenge providers and payers in the United States and elsewhere. Recent literature has demonstrated that the prices of care may constitute much of the problem. The magnitude of the issue suggests that progress in this area will be slow.

An alternative approach to reducing health care expenses may be the substitution of lower-cost services by health care providers. Much of the expenses generated by health care providers come from high-cost services such as inpatient hospital care. Shifting a portion of these expenses to less intense settings has the potential for reducing the costs of care.

This study reviewed examples of approaches to this process at the community level in the metropolitan area of Syracuse, New York. They involved provider-driven programs developed and implemented at the community level. This study was limited to these specific approaches.

The Subacute and Complex Care Programs were developed by the Syracuse Hospitals and the Hospital Executive Council to reduce the expenses of extended hospital stays that are currently provided in hospitals. They focused on movement of patient days for services such as dialysis, intravenous therapy, and expensive medications from inpatient acute care to nursing homes.

These programs involved costs of approximately $\$ 7100$ - $\$ 10,600$ per patient compared with costs of $\$ 12,600-\$ 25,000$ for extended stays in hospitals. The savings were generated by reducing high-cost stays and were realized by the sponsoring provider hospitals.

The study suggested that substantial savings were generated in the service area of the Syracuse hospitals by reducing adult medicine and adult surgery inpatient hospitalization rates. These savings were produced through the implementation of medical observation and ambulatory care programs for adult medicine patients and ambulatory surgery programs for adult surgery patients.

The annual savings generated by reduction of hospitalization for these services were substantial, $\$ 4,600,000$ for 2017 compared with 2011 . They were realized by the payers who otherwise would have sponsored the inpatient admissions that were avoided.

These programs for reducing health care expenses involved a less comprehensive alternative for reducing prices in this sector of the economy. This approach may have greater potential for implementation by providers and their communities.

\section{Conflicts of Interest}

The authors declare there are no conflicts of interests regarding this paper.

\section{References}

[1] Dentzler, S. (2011) Urgent Measures for an Old Problem. Health Affairs, 30, 1626. https://doi.org/10.1377/hlthaff.2011.0961 
[2] Meyer, H. (2019) As Value Based Efforts Lag, Push for Price Regulation Gains Momentum. Modern Healthcare, 49, 6-7.

[3] Lathi, S. (2019) Hospitals Don't Want Cost Debate to Creep into Surprise Billing Legislation. Modern Healthcare, 49, 8.

[4] Hadley, J. (1995) Hospital Price Regulation: Evidence and Implications for Health Care Reform. Health Care Policy and Regulation. Topics in Regulatory Economics and Policy Series, Vol. 20. Springer, Boston.

https://doi.org/10.1007/978-1-4615-2219-5_8

[5] Hyman, H.H. (1982) Health Planning: A Systematic Approach. Oxford Publishing, London.

[6] Tedeschi, P.I., Wolfe, R.A. and Griffith, J.R. (1990) Micro Area Variation in Hospital Use. Health Services Research, 24, 729-740.

[7] Kinickman, J.R. and Foltz, A.M. (1985) A Statistical Analysis of Reasons for East West Differences in Hospital Use. Inquiry, 22, 45-58.

[8] Chassin, M.R., Brook, R.H., Park, R.E., Kessey, J., Fink, A., Kahn, K., Merrick, N. and Solomon, D.H. (1986) Variations in the Use of Medical and Surgical Services by the Medicaid Population. New England Journal of Medicine, 315, 285-290. https://doi.org/10.1056/NEJM198601303140505

[9] Riley, G.F. (2007) Long Term Trends in the Concentration of Medicare Spending. Health Affairs, 26, 808-814. https://doi.org/10.1377/hlthaff.26.3.808

[10] Lagoe, R., Pasinski, T., Kronenberg, P., Quinn, T. and Schaengold, P. (2006) Linking Health Services at the Community Level. Canada Healthcare Quarterly, 9, 60-65. https://doi.org/10.12927/hcq..18229 